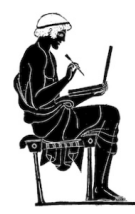

\title{
"Áurea Afrodite" e a ordem cósmica de Zeus na poesia hesiódica ${ }^{1}$ \\ "Golden Aphrodite" and Zeus's cosmic order in Hesiodic poetry
}

\author{
Juarez Oliveira ${ }^{2}$ \\ e-mail: j.oliveira@usp.br \\ orcid: http://orcid.org/0000-0003-4566-6909
}

\section{DOI: https://doi.org/10.25187/codex.v7i2.29684}

RESUMO: Após uma breve contextualização acerca da concepção de fórmula, defende-se que a figura de Afrodite, sobretudo quando apresentada

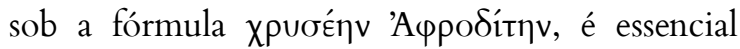
para compreendermos a dinâmica da linhagem dos heróis e da decisão de Zeus pelo seu fim na poesia hexamétrica grega arcaica. Associada à preposição $\delta i \alpha$, a fórmula teonímica é utilizada em contextos nos quais seres que ameaçam a ordem e o poder de Zeus são gerados, incluindose aí a própria linhagem dos heróis.

PALAVRAS-CHAVE: Afrodite; ordem cósmica de Zeus; linhagem dos heróis; criaturas prodigiosas; poesia hesiódica

\begin{abstract}
After a brief presentation about the notion of formula, this paper argues that Aphrodite, mainly when presented under the

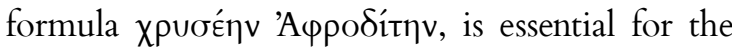
understanding of the dynamics of the race of the heroes and Zeus's decision to put an end to it in Greek early hexameter poetry. Associated with the preposition $\delta 1$ á, this theonimic formula is used in contexts where beings that threaten the order and power of Zeus are born, the race of heroes included.
\end{abstract}

KEYWORDS: Aphrodite; Hesiodic poetry; race of the heroes; prodigious creatures; Zeus's cosmic order

\footnotetext{
1 O presente trabalho foi realizado com apoio da Coordenação de Aperfeiçoamento de Pessoal de Nível Superior Brasil (CAPES) - Código de Financiamento 001.

2 Mestrando (2018-atual) do Programa de Pós-Graduação em Letras Clássica e Vernáculas da Faculdade de Filosofia, Letras e Ciências Humanas da Universidade de São Paulo, Brasil, sob orientação do Prof. Dr. Christian Werner, bolsista CAPES - Coordenação de Aperfeiçoamento de Pessoal de Nível Superior.
} 


\section{A concepção de fórmula}

Na seminal definição de Milman Parry, fórmula é "um grupo de palavras que é regularmente empregado sob as mesmas condições métricas para expressar uma dada ideia essencial"3. O que subjaz a essa definição é a noção de que o conteúdo semântico das palavras individuais do conjunto formular escolhido pelo poeta é menos relevante que o espaço métrico a ser preenchido. Nesse sentido, para citar uma das fórmulas que Parry usa como exemplot, $\theta \varepsilon \dot{\alpha}$

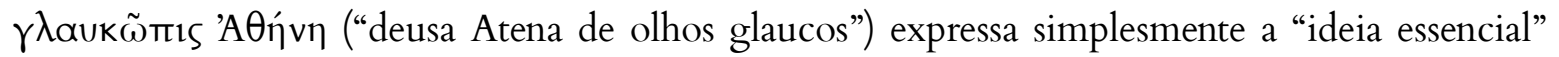
Atena, sendo semanticamente irrelevante a caracterização da deusa por meio de seus olhos, cuja função única seria preencher dado espaço métrico. É claro, no entanto, que em certa medida tal caracterização é tradicional, e assim também a de quaisquer outros personagens cujas fórmulas são compostas por adjetivos ou epítetos.

Na esteira do trabalho de Parry, Albert B. Lord, que se dedicou ao estudo das tradições poéticas iugoslavas, entende a fórmula de modo semelhante ao de seu mentor, mas aprofunda a ideia ao defini-la como integrante de uma linguagem poética: "as fórmulas são frases, cláusulas e

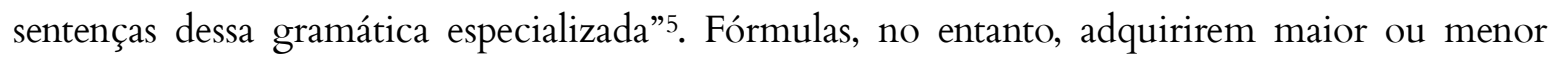
grau de estabilidade de acordo com a recorrência das ideias às quais elas remetem ${ }^{6}$, de modo que elas "expressarão os nomes dos atores, as ações, tempo e lugares principais".

A ideia de fórmula como linguagem é retomada por John M. Foley, para quem elas são o que ele chama de sêmata, isto é, "símbolos tangíveis que apontam para questões ou ideias maiores que, de outra forma, permaneceriam ocultas ou secretas, janelas que se abrem para realidades emergentes que não podem ser conhecidas de outra forma". Enquanto símbolos, as fórmulas "funcionam como marcadores idiomáticos" que "transmitem referencialidade tradicional". A concepção de referencialidade tradicional de Foley leva em conta que o público dos poemas é parte de um circuito comunicacional ${ }^{10}$, no qual as fórmulas inserem "a variedade

\footnotetext{
3 Parry (1971, p. 272). Todas as traduções de obras em língua estrangeira, incluindo o grego, são de minha autoria, exceto quando indicado.

4 Parry (1971, p. 272).

5 Lord (1971, p. 36).

${ }^{6}$ Lord (1971, pp. 34, 43).

7 Lord (1971, p. 34).

${ }^{8}$ Foley (1999, p. 3).

9 Foley (1999, p. 4).

${ }^{10}$ Foley (1999, pp. 15-16).
} 
de instâncias individuais em um contexto familiar, identificável" ${ }^{11}$, contexto esse que se encontra no que Foley chama de apparatus fabulosus, que é o conjunto de histórias conhecidas da tradição

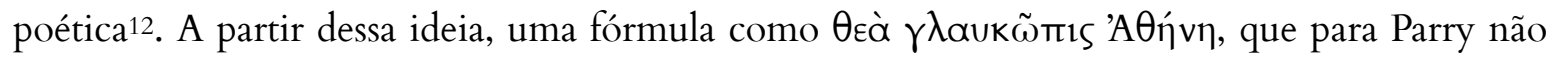
diz senão "Atena", funciona, na perspectiva de Foley, por sinédoque, isto é, refere-se a um "conceito holístico tradicional" por meio de uma parte sua que "projeta uma riqueza complexa e imanente" 13 .

Tendo em vista esse breve e parcial panorama da evolução do conceito de fórmula, a concepção que adoto no presente trabalho é a de que fórmulas são, além de recursos instrumentais para a composição poética, unidades semânticas que remetem a contextos míticos mais amplos e tradicionais, permitindo ao público ouvinte dos poemas hexamétricos arcaicos estabelecer relações de sentido a partir do conteúdo poético-narrativo.

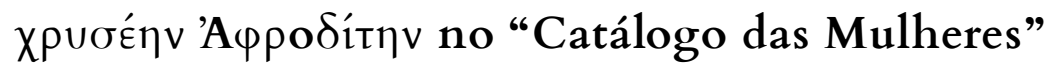

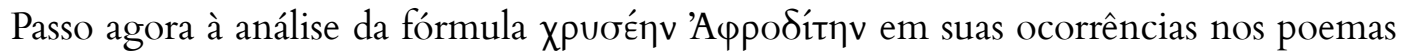
hesiódicos, a fim de demonstrar como ela relaciona heróis e criaturas prodigiosas ${ }^{14}$, além de atribuir importante papel à deusa no contexto da ordem cósmica de Zeus e da decisão deste deus pelo fim da linhagem dos heróis.

Considerado como continuação da Teogonia na Antiguidade15, o Catálogo das Mulheres ${ }^{16}$ hesiódico relata o enlace amoroso dos deuses com mulheres humanas e a prole

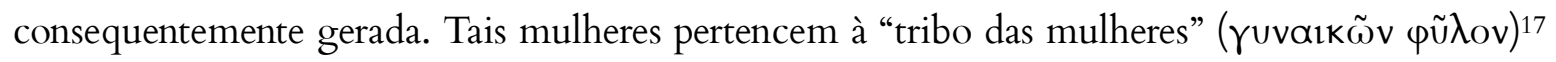
e dão à luz a chamada linhagem dos heróis ${ }^{18}$, embora elas mesmas não sejam designadas como heroínas por termo grego algum na poesia hexamétrica grega arcaica19. Tais enlaces não

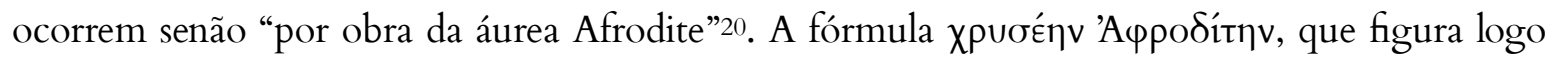
no quarto verso do proêmio associada à preposição $\delta ı \alpha$, atribui à deusa a razão pela qual as

\footnotetext{
11 Foley (1999, p. 18).

12 Foley (1999, p. 25).

${ }^{13}$ Foley (1999, pp. 19-20).

14 Adoto, ao longo do trabalho, a expressão “criaturas prodigiosas” conforme proposta de Zanon (2018, p. 98) a partir da análise dos termos que se referem às criaturas míticas que a crítica convencionou chamar de monstros. Acerca da discussão, cf. adiante "Heróis e criaturas prodigiosas".

15 Cf. Hunter $(2005$, p. 1).

16 Doravante Catálogo.

17 Hes. fr. 1 Most, v. 1. Todas as traduções do Catálogo seguem a edição e numeração de Glenn W. Most (2007), de modo que, doravante, não indicarei mais o editor.

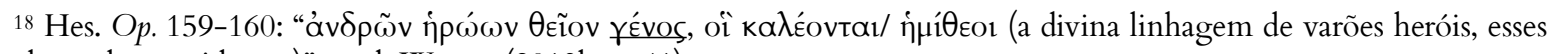
chamados semideuses)”; trad. Werner (2013b, p. 41).

19 Graziosi \& Haubold (2005, p. 99).

${ }^{20}$ Hes. fr. 1.4.
} 
mulheres "afrouxaram as cintas [...] unindo-se aos deuses"21, gerando assim a linhagem dos heróis:

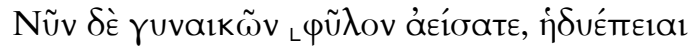

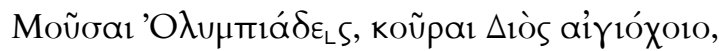

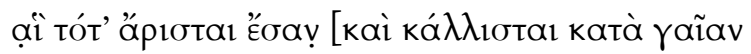

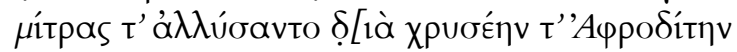

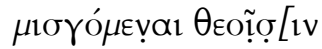

Agora, a tribo das mulheres cantai, Musas Olímpias de doce fala, filhas de Zeus porta-égide, elas que um dia foram as mais nobres e [belas na terra e afrouxaram as cintas $p$ [or obra da áurea Afrodite unindo-se $[a o]_{s}$ deuses $^{22}$

Embora essa ocorrência da fórmula seja um suplemento que Most propõe para esse fragmento do proêmio a partir da possibilidade de poder ler a primeira letra de $\delta$ ı́a, há pelo menos dois fatores que corroboram a hipótese: 1) a fórmula é recorrente no poema; e 2) ela ocorre sobretudo em contextos eróticos.

No Catálogo, essa fórmula ocorre outras sete vezes ${ }^{23}$ e, destas, duas são em associação com $\delta ı \alpha$, sempre em contextos de enlace amoroso com geração de prole, como:

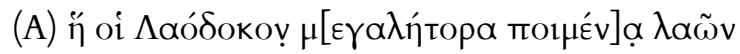

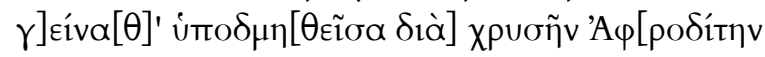

Ela para ele ${ }^{24}$ Laódoco, v[iril past]or de povos, g]er[ou, subju[gada por obra] da áurea Af[rodite 25

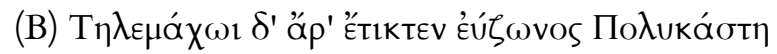

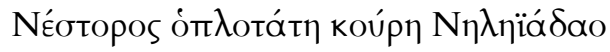

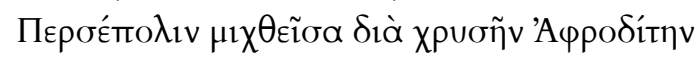

Para Telêmaco a bem-cingida Policasta, de Nestor Nelida a mais jovem filha, gerou Persépolis, unida a ele por obra da áurea Afrodite 26

\footnotetext{
21 Hes. fr. 1.4-5.

22 Hes. fr. 1.1-5.

23 Quatro no genitivo (Hes. fr. 48.31,35; 123.17; 154.5), três no acusativo (fr. 1.4; 19.35; 168.3) e uma no dativo, cf. Hes. fr. 27.25 .

24 Timandra para Equemo.

25 Hes. fr. 19.34-35.

${ }^{26}$ Hes. fr. 168.
} 
Das outras cinco ocorrências, todas sem a preposição, uma tem contexto indefinido devido ao caráter muito fragmentário da passagem ${ }^{27}$; duas se dão em contextos eróticos onde o enlace amoroso não se concretiza 28 ; e outras duas ocorrem em um contexto de comparação entre uma mortal e Afrodite, em chave positiva relacionada à beleza das moças. ${ }^{29}$ Dessas últimas duas ocorrências, uma merece destaque por tratar justamente de Helena, por quem diversos heróis se mobilizarão a fim de conquistar sua mão em casamento, momento fundamental na sequência de eventos que resultará na Guerra de Troia:

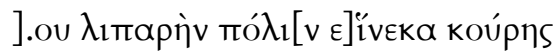

$$
\begin{aligned}
& \text { ī E⿱一𫝀] } \\
& \text {... a brilhante cidad[e p]ela filha }{ }^{30} \\
& \text { que] possuía [a bele]za da áurea Af[rodi]te. }{ }^{31}
\end{aligned}
$$

Com essas ocorrências em vista, pode-se concluir que, no contexto do Catálogo, Afrodite tem papel relevante na geração da linhagem dos heróis: é a sua influência que faz com que o enlace entre deuses e mulheres ocorra, resultando na geração desses seres. Se levarmos em consideração o Hino Homérico a Afrodite ${ }^{32}$, isso se apresenta como problema: nesse poema, a deusa faz, à revelia de Zeus, com que deusas e deuses envolvam-se com humanos, gerando assim filhos mortais. Como discutirei adiante, essa é uma prole que se configura como potencial ameaça à ordem de Zeus, tanto pelo seu poder, similar ao das criaturas prodigiosas, quanto pelas "linhas borradas" entre a eternidade e a potência divinas e a mortalidade e limitação humanas.

Segundo o Hino, Afrodite "nos deuses desperta doce desejo" e "as greis dos homens mortais submete"; afinal "os trabalhos da bem coroada Citeréia a todos concernem" 33 . Entretanto, ela não persuade nem engana o coração de Atena, Ártemis e Héstia:

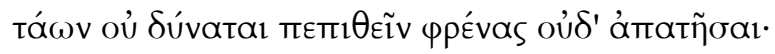

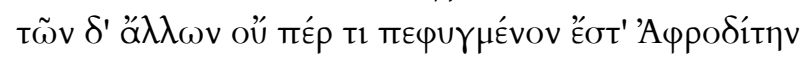

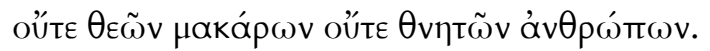

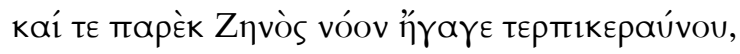

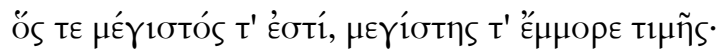

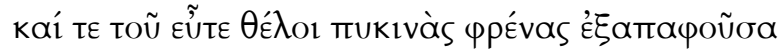

\footnotetext{
${ }^{27}$ Hes. fr. 123.

28 Hes. fr. 48.31, 35.

29 Hes. frr. 27.25; 154.4-5.

30 Helena.

${ }^{31}$ Hes. fr. 154.4-5.

32 Doravante Hino.

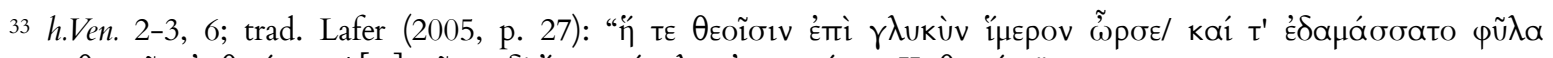

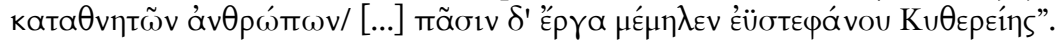




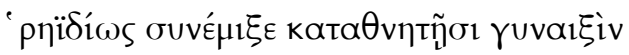

A esses corações não pode persuadir nem enganar, mas dos outros nenhum consegue de Afrodite escapar nem dos deuses felizes nem dos homens mortais; conduziu até o espírito do frui-raios Zeus, que é grandíssimo e de grandíssima honra partilha; e se ela quiser, dele enganando o denso coração, facilmente o faz unir-se a mulheres mortais, fazendo-o esquecer-se de Hera, irmã e esposa [... $]^{35}$

O que essa passagem demonstra é quão potente é Afrodite frente aos outros deuses e sobretudo o perigo que representa para Zeus, já que é capaz de dominar-lhe o senso e fazê-lo unir-se a mortais. Sua potência manifesta-se já no início do hino com o uso da fórmula

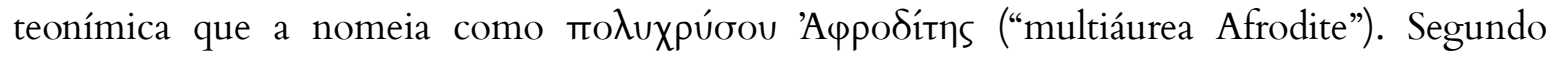
Deborah Boedeker, "esse nome-epíteto é claramente uma expansão da conhecida fórmula

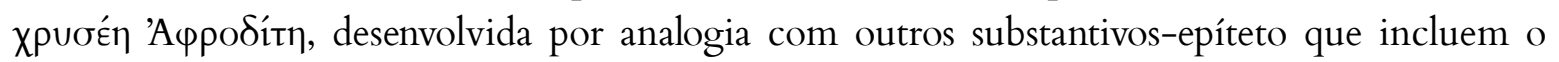
elemento по $\lambda u \chi \rho v \sigma-" 36$.

Assim sendo, Afrodite é apresentada tanto no Hino quanto no Catálogo por meio de uma fórmula que a vincula a contextos em que seu poder colabora para a geração da linhagem dos heróis, o que pode caracterizar a deusa como uma potencial oponente de Zeus. No contexto do Hino, em que a oposição entre ele e Afrodite é marcada, o deus revidará, fazendo com que a deusa, assim como ela faz com os demais deuses, apaixone-se por um mortal, incutindo nela "doce desejo de se unir a um homem mortal" 37 , para que "não mais pudesse ela [...] com atrevido sorriso, gabar-se de induzir à união deuses e mulheres mortais" ${ }^{38}$. Desse enlace também ela gerará um filho, o herói Eneias.

\section{Heróis e criaturas prodigiosas}

Nesse ponto, para compreendermos melhor em que medida Afrodite é importante no contexto cósmico da ordem de Zeus, é preciso ter em vista o que sejam a linhagem dos heróis e também as criaturas prodigiosas.

\footnotetext{
34 Para o texto grego do Hino, uso a edição de Càssola (1975).

35 h.Ven. 34-40; trad. Lafer (2005, p.28).

${ }^{36}$ Boedeker (1974, p. 26)

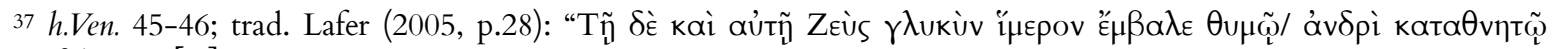
$\mu \imath \chi \theta \hat{\mu} \mu \varepsilon \vee \propto \imath[. .] ”$.

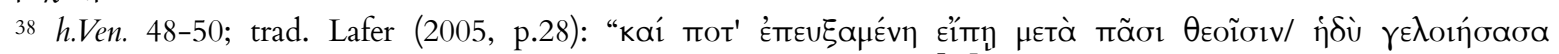

} 
Nomeados, em particular, de $\dot{\eta} \mu \hat{i} \theta \varepsilon o 1$ ("semideuses") na poesia hesíodica ${ }^{39}$, os heróis compõem uma linhagem que se diferencia das outras quatro que integram o mito hesiódico das cinco linhagens, narrado em Trabalhos e Dias, na medida em que ela é dita "mais justa e melhor" ${ }^{40}$. Essa linhagem tem o seu modo de vida marcado pelas guerras e pela prática de navegação ${ }^{41}$, algo que se evidencia no modo como Hesíodo descreve o seu fim:

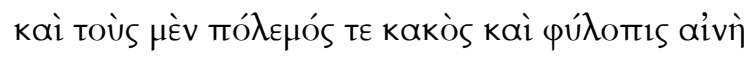

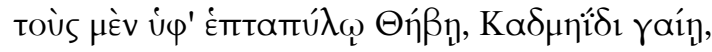

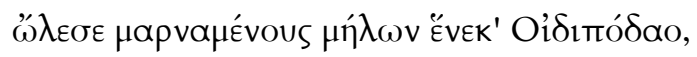

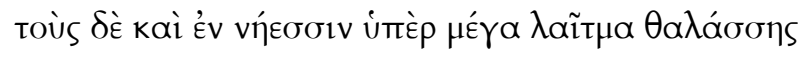

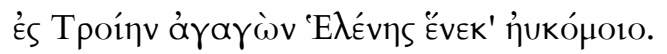

E a eles guerra danosa e prélio terrivel, a uns sob Tebas sete-portões, na terra cadmeia, destruiu, ao combaterem pelos rebanhos de Édipo, a outros, nas naus, sobre o grande abismo do mar, levando a Troia por conta de Helena bela-coma. ${ }^{42}$

Mesmo não fazendo parte do âmbito divino, os heróis podem, no contexto do Catálogo, envolver-se social e sexualmente com os deuses, vivendo assim em parcial proximidade com eles ${ }^{43}$, "pois comunais eram então os banquetes, e comunais os conselhos/ entre os deuses imortais e os homens mortais" 44 . De fato, essa linhagem é marcada no Catálogo "como um período excepcional e efêmero da proximidade humana com o divino" ${ }^{45}$.

Em outros poemas, como é o caso da Ilíada, por exemplo, essa proximidade entre deuses e heróis se apresentará como origem de desentendimentos entre os deuses: cumprindo sua promessa a Tétis de conceder glória a Aquiles e também tentando proteger Sarpédon, Zeus é repreendido por Hera; esta e Atena, deixando que Afrodite favoreça Páris mais do que elas favorecem Menelau, são repreendidas por Zeus46. Tais desentendimentos são, assim, contrários à harmonia pretendida por Zeus entre os deuses, levando-os a disputas que poderiam resultar na deposição do pai de deuses e homens.

\footnotetext{
${ }^{39}$ Cf. Hes. Op. 160 e Hes. Fr. 155.100.

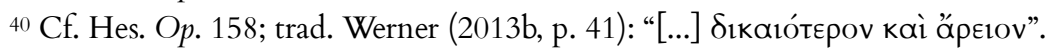

${ }^{41}$ Cf. Clay (2005, pp. 26-27).

42 Hes. Op. 161-165; trad. Werner (2013b, p. 41), grifos meus.

43 Cf. Clay (2005, pp. 26-27).

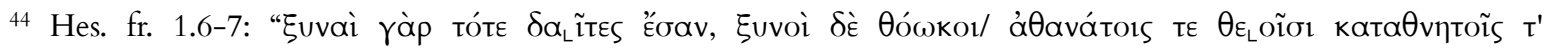

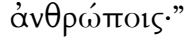

45 Clay (2005, p. 28).

${ }^{46}$ Cf., a respeito da promessa de Zeus a Tétis, Il. 1.536 ss.; a respeito da proteção de Sarpédon, Il. 16.431 ss.; a respeito do favorecimento das deusas, Il. 4.5 ss.
} 


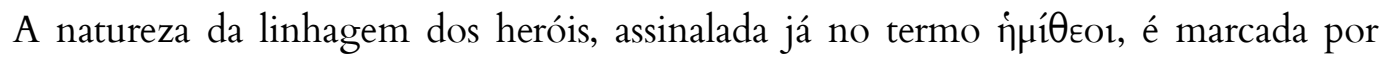
uma ambiguidade que provém da sua genealogia ancestral: embora descendam de deuses, quer em nível primário (como filhos), quer em níveis secundários (como netos etc.), eles são sempre mortais, ainda que detentores de um potencial físico proveniente, como já mencionado, da sua ascendência divina ${ }^{47}$.

Nesse sentido, da perspectiva do Catálogo, os heróis são entidades humanas que podem ser vistas como parte integrante do momento de desenvolvimento final do cosmo sob a ordem de Zeus, quando o lugar dos seres vivos no mundo ainda está sendo estabelecido, de modo que, assim como as criaturas prodigiosas, os heróis são seres de imenso poder que podem vir a romper a ordem pretendida por Zeus. Disso advém sua decisão de destruir essa linhagem 48 .

O que são as criaturas prodigiosas, que são referidas sobretudo como monstros pela crítica, é um debate que só mais recentemente ganhou impulso. Em seu estudo seminal sobre os poemas hesiódicos, Jennny Strauss Clay entende essas figuras, que fazem parte, em particular, das genealogias apresentadas na Teogonia ${ }^{49}$, como entidades de caráter anômalo e perigoso porque desafiam classificações e limites, além de se constituírem como seres híbridos, já que apresentam características geralmente díspares ou contraditórias, como "o humano e o bestial [...], mortal/ imortal, jovem/velho e masculino/feminino" 50.

Em boa medida, contra essa visão, que é predominante nos estudos clássicos, coloca-se Camila Zanon, que em seu recente Onde vivem os monstros (2018) demonstra como a crítica costuma projetar anacronicamente o entendimento moderno do que seja um monstro sobre esse conjunto de criaturas que participa do desenvolvimento do cosmo apresentado pela poesia hexamétrica grega arcaica51. Segundo ela:

"Mais do que o hibridismo ou o excesso de alguma característica ou mesmo as disparidades entre velhice/juventude ou mortalidade/imortalidade, esses seres se apresentam como possuidores de um caráter extraordinário ou fantástico, que extrapola a observação da realidade imediata" 52 .

Referidos sobretudo pelos substantivos tépas, $\pi \dot{\lambda} \lambda \omega \rho$ e $\pi \dot{\lambda} \lambda o \rho o v$ e pelos adjetivos

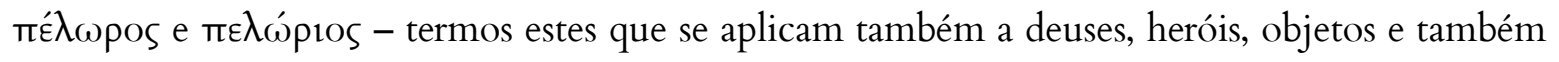
fenômenos naturais ${ }^{53}$-, essas criaturas devem ser entendidas por meio de três noções básicas:

\footnotetext{
47 Cf. Nagy (2006, \$70).

48 Cf. Koning (2017, pp. 101-103).

${ }^{49}$ Cf. especialmente o chamado "catálogo dos monstros” em Hes. Th. 270-336.

50 Clay (2003, pp. 151-152).

51 Cf. Zanon (2018, p. 245).

52 Zanon (2018, pp. 165-166).

${ }^{53}$ Cf. Zanon (2018, p. 68).
} 
“[...] primeiro, a noção de algo extraordinário e, por isso, espantoso e impressionante, podendo ou não infundir o sentimento de terror; segundo, e derivada da primeira, a noção de portento ou prodígio enquanto manifestação do ato comunicativo da divindade com o âmbito humano, considerado, portanto, uma mensagem enviada pelos deuses; terceiro, uma noção de enormidade espantosa $[\ldots]{ }^{354}$.

A partir desse entendimento do que sejam os monstros, Zanon sugere então que eles sejam referidos não como tais, mas como criaturas prodigiosas ${ }^{55}$.

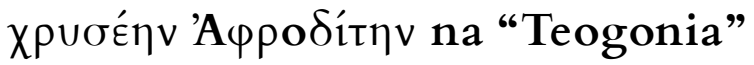

Tendo-se em vista, assim, que tanto heróis quanto criaturas prodigiosas são seres de grande poder que participam do âmbito divino do cosmo, podemos então verificar uma das

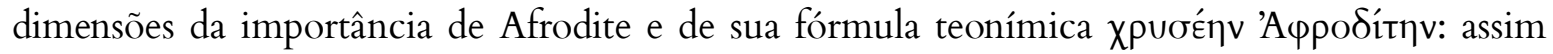
como essa fórmula vigora no Catálogo em meio ao contexto da geração de heróis, ela também ocorre na Teogonia, associada à preposição $\delta$ ı́a, no relato da geração de diversas figuras humanas, como Medeia (958-62), Focos (1003-5) e Ágrio, Latino e Telégono (1011-14), todas elas integrantes do período em que vigora a linhagem dos heróis, e também na geração de duas criaturas prodigiosas, a saber, Tifeu e Gerioneu.

Tifeu, o derradeiro opositor de Zeus, é o primeiro a ser gerado sob a fórmula teonímica. Segundo Hesíodo:

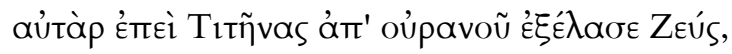

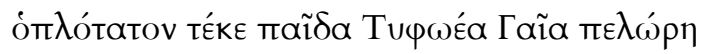

Тарта́ро év

Mas depois que Zeus expulsou os Titãs do céu,

gerou Tifeu, o filho mais novo, a portentosa Terra

em amor por Tártaro por obra da áurea Afrodite (... ${ }^{56}$

Depois de Tifeu, Gerioneu, o gigante de três cabeças que Héracles terá de eliminar em Eriteia, é a única outra criatura prodigiosa cujo nascimento é relacionado a Afrodite, nesse caso

\footnotetext{
${ }^{54}$ Zanon (2018, p. 67).

55 Cf. Zanon (2018, p. 98).

${ }^{56}$ Hes. Th. 820-2; trad. Werner (2013a, p.89), adaptada; grifos meus.
} 


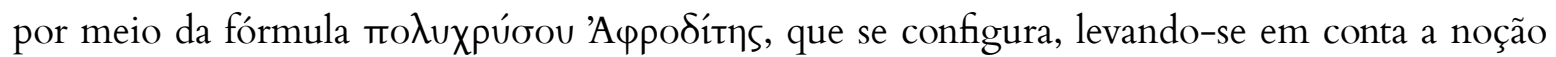

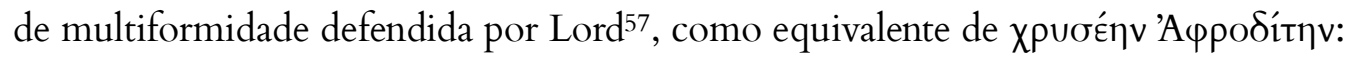

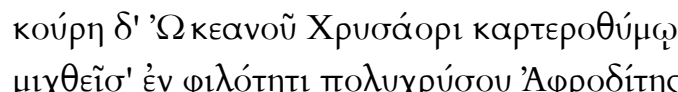

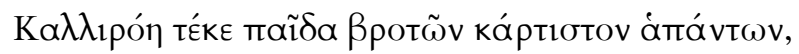

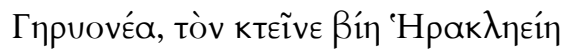

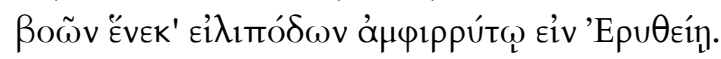

A filha de Oceano, após a Espadouro ânimo-vigoroso

unir-se em amor de Afrodite muito-ouro,

Bonflux, gerou o filho mais vigoroso de todos os mortais,

Gerioneu, a quem matou a força heráclida

pelos bois passo-arrastado em Eriteia banhada por correntes. 58

O fato de que essas duas criaturas nasçam sob o auspício de Afrodite é significativo, já que cada uma delas se configura numa ameaça a duas dimensões distintas do cosmo, isto é, ao passo que Tifeu se opõe à ordem cósmica de Zeus, sendo assim uma ameaça sobretudo para os deuses, Gerioneu se apresenta exclusivamente como ameaça aos humanos.

Uma vez que Gerioneu e outras criaturas prodigiosas como ele se constituirão como ameaça unicamente aos seres humanos ${ }^{59}$, parece-me distintivo que Tifeu seja o único dentre essas criaturas a ser relacionado a Afrodite: se, por um lado, ele é um descendente prodigioso de Gaia que ameaça a ordem cósmica de Zeus, por outro, há criaturas prodigiosas, também descendentes dela, que colaboram para a vitória do deus, servindo-lhe de aliados, como é o caso dos Ciclopes, que lhe dão o trovão e forjam o raio ${ }^{60}$, e também dos Centímanos, que lhe servem de artilharia contra os Titãs na Titanomaquia ${ }^{61}$.

Como examina Zanon, Tifeu não só é o único filho de Gaia a nascer de uma "união da deusa presidida por Afrodite" 62 como também é fruto do enlace entre dois deuses primordiais, isto é, Gaia e Tártaro, o que faz com que o nascimento de Tifeu seja “um regresso literal a uma

57 Cf. Lord (1960, pp. 99-100), para quem o poeta, diferentemente dos receptores letrados modernos do poema, parte de um esqueleto narrativo padrão, mas não de um texto fixo que deve ser reproduzido cena a cena, nem palavra por palavra. Disso decorre que cada performance, embora apresente a mesma história, o faz com fórmulas e temas variáveis, sem que haja algo original do qual o que é apresentado derive; sendo assim, tanto as fórmulas quanto os temas são multiformas.

${ }^{58}$ Hes. Th. 979-983; trad. Werner (2013a, p. 99), adaptada; grifos meus.

59 Podemos elencar aqui, por exemplo, a Hidra de Lerna (Hes. Th. 313 ss.) e o Leão de Nemeia (Hes. Th. 327 ss.), ambas criaturas prodigiosas que, sob comando de Hera, opõem-se a Héracles e acabam vencidas por ele. A esse respeito, cf. Zanon (2018, p. 164).

${ }^{60}$ Cf. Hes. Th. 139-141; 501-505.

61 Cf. Hes. Th. 664-675.

62 Zanon (2018, p. 144). 
era mais antiga"63. Em última análise, conforme afirma Clay, para que Zeus estabeleça sua regência sobre o cosmo é preciso que ele suprima a fecundidade de Gaia, neutralizando "a estratégia dela de sempre se aliar à nova geração contra a anterior a fim de promover mudança às custas da estabilidade cósmica" ${ }^{64}$.

Nesse sentido, portanto, é notável que o nascimento de Tifeu seja presidido por Afrodite, já que o nascimento dela foi resultado justamente da castração de Urano, um processo pelo qual ele não só foi separado de Gaia como teve sua própria fecundidade suprimida. Dessa forma, é como se Afrodite, promovendo a união entre Gaia e Tártaro, favorecesse a possibilidade do estabelecimento de um cosmo sob uma ordem às avessas, porque, se a primeira linhagem de Gaia era, de certa forma, parte ctônica e parte celestial, a segunda será inteiramente ctônica, uma vez que Tártaro se situa "no recesso da terra largas-rotas" 65 . Governada por Tifeu caso não fosse vencido por Zeus, essa ordem seria marcada pelas características atribuídas ao seu governante, que é dito "assombroso, soberbo e sem lei" ${ }^{\circ}$, e cujas ações têm uma "natureza 'impossível de lidar"”67.

\section{Conclusão}

Tendo em vista o que se demonstrou até aqui, concluo que Afrodite, sob sua caracterização formular multiforme áurea, é a deusa responsável pela geração não só da linhagem dos heróis, mas também de criaturas prodigiosas - ambos conjuntos de seres que representam, embora não em sua totalidade, uma ameaça potencial à ordem de Zeus, devido, sobretudo, ao seu poder físico. Nesse sentido, ainda que de forma indireta, já que Afrodite não confronta Zeus diretamente, a deusa pode se apresentar, em certo instante da história do cosmo, como sua antagonista, algo que, embora ausente no Catálogo e mesmo na Ilíada e Odisseia, alguns poemas da tradição como o Hino põem em cena e desenvolvem, mas de forma tal que a deusa acaba por ser totalmente reintegrada à ordem estabelecida pelo deus.

\section{Referências bibliográficas:}

BOEDEKER, Deborah D. Aphrodite's entry into Greek epic. Leiden: Brill, 1974.

CÀSSOLA, Filippo. Inni omerici. Milão: Fondazione Lorenzo Valla, 1975.

CLAY, Jenny S. The beginning and end of the Catalogue of Women and its relation to Hesiod In: HUNTER, Richard. (Org.) The Hesiodic Catalogue of Women: constructions and reconstructions. New York: Cambridge University Press, 2005, pp. 25-34.

\footnotetext{
${ }^{63}$ Zanon (2018, p. 145); cf. ainda Clay (2003, p. 25, n. 37).

${ }^{64}$ Clay (2003, p. 26).

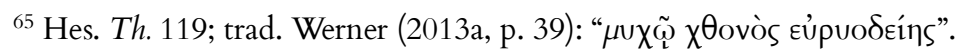

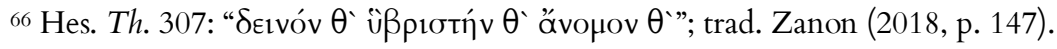

67 Zanon (2018, p. 148).
} 
. Hesiod's Cosmos. Cambridge: Cambridge University Press, 2003.

FOLEY, John M. Homer's traditional art. Pennsylvania: The Pennsylvania State University Press, 1999.

GRAZIOSI, Barbara; HAULBOLD, Johannes. The Resonance of Epic. London: Duckworth, 2005.

HUNTER, Richard. (org.) The Hesiodic Catalogue of Women: constructions and reconstructions. New York: Cambridge University Press, 2005.

KONING, Hugo. Helen, Herakles, and the end of the heroes. In: TSAGALIS, C. (org.) Poetry in fragments: Studies on the Hesiodic corpus and its afterlife. Berlin: De Gruyter, 2017, p. 99-114.

LAFER, Mary M. C. N. Engenhos da sedução: Estudo sobre o Hino Homérico a Afrodite. 152 p. Tese (Doutorado em Língua e Literatura Grega) - Faculdade de Filosofia, Letras e Ciências Humanas, Universidade de São Paulo, São Paulo, 2005.

LORD, Albert. The singer of tales. Nova Iorque: Atheneum, 1971.

MOST, Glenn W. Hesiod: The Shield; Catalogue of Women; Other Fragments. London: Harvard Universty Press, 2007.

NAGY, Gregory. The Epic Hero. Washington: Center for Hellenic Studies, 2006. Disponível em <http://nrs.harvard.edu/urn-3:hlnc.essay:Nagy.The_Epic_Hero.2005>. Acesso em: 01 out. 2019.

PARRY, Milman. The making of Homeric verse. Oxford: Oxford University Press, 1971.

TSAGALIS, C. (org.) Poetry in fragments: Studies on the Hesiodic corpus and its afterlife. Berlin: De Gruyter, 2017.

WERNER, Christian. Hesíodo: Teogonia. São Paulo: Hedra, 2013a. . Hesíodo: Trabalhos e Dias. São Paulo: Hedra, 2013b.

ZANON, Camila A. Onde vivem os monstros: criaturas prodigiosas na poesia de Homero e Hesíodo. São Paulo: Humanitas, 2018.

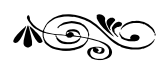

